\title{
Similitudes entre Ontogenia y Regeneración Ósea Post-fractura
}

\author{
Similarities between Ontogeny and Post-fracture Bone Regeneration
}

Carolina Smok ${ }^{*, * *}$ \& Mariana Rojas**

SMOK, C. \& ROJAS, M. Similitudes entre ontogenia y regeneración ósea post-fractura. Int. J. Morphol., 34(4):1293-1299, 2016.

RESUMEN: La osificación es un proceso que ocurre durante la embriogénesis al iniciar el periodo fetal. Se caracteriza por una condensación de células mesenquimáticas con una bipotencialidad condro y osteogénica para formar tejido óseo mediante osificación endocondral y membranosa respectivamente. La regeneración ósea es la respuesta generada con el fin conseguir la restitución del tejido tras un trauma. Este evento se caracteriza por la formación de un callo perióstico secundario cuya ontogénesis sigue los patrones embrionarios al presentar ambos tipos de osificación, además de la regulación molecular propia durante la etapa fetal, concluyendo que ambos procesos están íntimamente relacionados durante la ontogenia del individuo, con la excepción del proceso inflamatorio generado luego de una injuria.

PALABRAS CLAVE: Osificación; Regeneración; Fractura ósea.

\section{INTRODUCCIÓN}

El desarrollo embrionario consta de una serie de eventos dentro de los cuales destaca la formación de los huesos, marcando la diferencia entre la etapa embrionaria y fetal. Este proceso involucra células mesenquimáticas que se diferencian en distintas líneas celulares, además de un patrón molecular específico para permitir esta diferenciación, el cual se repite durante la regeneración ósea tras sufrir un trauma. El objetivo de esta revisión es realizar una comparación entre la osificación durante el desarrollo embrionario y la regeneración ósea post fractura.

La osificación de los huesos, que comienza junto con la vida fetal, continúa durante la ontogenia a través de la remodelación ósea, y en caso de injuria el organismo responde con la regeneración ósea, la cual sigue los patrones del normal desarrollo durante la embriogénesis (Ferguson et al., 1999; Shapiro, 2008; Shintaku et al., 2011; Soung do et al., 2012), con excepción de la inflamación asociada (Arvidson et al., 2011). Tanto en la formación del hueso como en su reparación, los procesos de osteogénesis y angiogénesis están fuertemente relacionados (Hsiong \& Mooney, 2006; Grellier et al., 2009; Clarkin \& Gerstenfeld, 2013; Marini et al., 2015), permitiendo la interacción entre las células encargadas de la formación ósea y las células endoteliales (Athanasopoulos et al., 2007; Wang et al., 2007; Marini et al.).
En la etapa fetal, la osificación comienza con la formación de una condensación mesenquimática cuyas células presentan una bipotencialidad condro y osteoprogenitoras (Tsang et al., 2015). Esta condensación de células se forma mediante la producción de N-cadherina, y su estado de agregación se mantiene gracias a la síntesis de fibronectina y $\mathrm{N}$ CAM estimulado por el factor de crecimiento transformante $\beta$ (TGF- $\beta$ ), punto en el cual comienzan los programas de diferenciación condrogénico y osteogénico para posteriormente dar paso a la osificación endocondral (Fig. 1) y membranosa respectivamente, dependiendo de los factores de transcripción (Carlson, 2014).

La regeneración ósea es la respuesta generada con el fin conseguir la restitución del tejido tras un trauma. Es un proceso complejo que involucra una interacción coordinada entre varias líneas celulares, factores de crecimiento y componentes de la matriz extracelular (Claes et al., 2012; Raggatt et al., 2014). Por otro lado en la reparación, el tejido que se forma es un tejido cicatricial, con características diferentes al original (Córdova, 2010). Según Davies \& Hosseini (2000), el hueso, además del tejido embrionario, es el único tejido del organismo que presenta la capacidad de completa restitución tras una lesión. Tras un trauma, se produce una respuesta inflamatoria y un hematoma inicial, con eritrocitos, trombocitos y fibrina (Córdova). Las células del coágulo

\footnotetext{
* Universidad Central de Chile, Facultad Ciencias de la Salud, Escuela de Enfermería, Santiago, Chile.

** Universidad de Chile, Facultad de Medicina, Programa de Anatomía y Biología del Desarrollo, Laboratorio de Embriología Comprada. Santiago, Chile.
} 
liberan interleuquinas y factores de crecimiento, provocando la invasión al sitio de la lesión de células precursoras de osteoclastos, linfocitos, macrofagocitos y células mesenquimáticas multipotenciales (Fernández-TresguerresHernández-Gil et al., 2006), para formar nuevos vasos sanguíneos, fibroblastos, y otras células de soporte que forman tejido de granulación entre los bordes de la fractura. Junto con esto, macrofagocitos y otras células derivadas de este tejido actúan para remover el hematoma inicial. Luego, los osteoclastos comienzan a reabsorber los bordes del hueso que se encuentran dañados y necróticos, y las células osteoprogenitoras de periostio proliferan (Frost, 1989; Einhorn, 1998; Day et al., 2000). Todo ello está regido por una serie de complejas interacciones entre factores de crecimiento, hormonas y citoquinas. En este proceso va a ser fundamental el aporte vascular, la síntesis proteica y la mineralización (Fernández-Tresguerres-Hernández-Gil et al.).

Dentro de las moléculas reguladores de quimiotaxis, mitosis y diferenciación bajo la influencia del factor de transcripción se encuentran el core binding factor 1, también llamado de Runx-2 (cbfa1), Wnt, Indian hedgehog (Ihh), genes que responden a hedgehog tales como GLi 1 y patched (Otc), también las proteínas morfogenéticas del hueso (BMP2, BMP3, BMP4, BMP-6 y BMP7), los factores de crecimiento fibroblástico FGF1 y FGF2, el factor de crecimiento derivado de plaquetas (PDGF), TGF $\beta$, metaloproteinasas (MMPs), y el factor de crecimiento endotelio vascular (VEGF) (Colnot et al., 2012; Kierszenbaum \& Tres, 2012; Carlson). Se ha demostrado que la participación del factor de transcripción Sox9 y las proteínas Runx-1, Runx-2 son esenciales durante la embriogénesis y la formación del callo cartilaginoso (Shintaku et al.). Sox9 es expresado por las células condroprogenitoras y presentan un rol crucial en la condrogénesis (Shintaku et al.; Murao et al., 2013; Carlson), mientras que Runx-1, Runx-2 y Runx-3 participan en los eventos de la osificación directa e indirecta (Carmeliet \& Jain, 2011; Soung do et al.) estimulando la diferenciación de osteoblastos (Carlson) y la angiogénesis durante la formación del hueso (Shintaku et al.). También se ha descrito la presencia del gen Osterix (Osx) como un factor necesario en la osificación y mineralización (Kierszenbaum \& Tres; Glynn et al., 2013; Carlson). Prx-1 es un gen de la caja homeobox necesario para el desarrollo de miembros, y su expresión es previa a Sox9 (Martin \& Olson, 2000), sin embargo su presencia no es indispensable. En cambio en el adulto sí es necesario para la formación del callo cartilaginoso, y su ubicación radica en las células multipotenciales presentes en el periostio (Soung do et al.) (Fig. 2).

Durante la osificación endocondral, los condrocitos proliferan y luego se diferencian en condrocitos prehipértróficos, los cuales sufren un aumento de volumen y pasan a la fase de hipertrofia (Fig. 1B) (Tsang et al.). En la medida que comienza la hipertrofia, las células del pericondrio adyacentes se diferencian en osteoblastos y secretan matriz ósea, mientras que los condrocitos maduros secretan vesículas de calcio hacia la matriz cartilaginosa (Einhorn; Claes et al., 2012; Tsang et al.), similar a lo que ocurre luego de una injuria, coincidiendo diversos investigadores que estas células liberan calcio entre los 10 y 14 días posterior a un trauma (Einhorn; Claes et al., 2012; Mirhadi et al., 2013) (Fig. 3A). Dentro de las proteínas estructurales podemos mencionar el colágeno tipo I para el hueso, y colágeno tipo II y X en cartílago, predominando este último en la fase hipertrófica. Estos condrocitos hipertróficos comienzan la producción de proteínas óseas como osteocalcina, osteonectina y osteopóntina, y de VEGF (Carlson).

La vascularización que permite el inicio de la osificación (Fig. 3B), proviene desde el pericondrio, permitien-

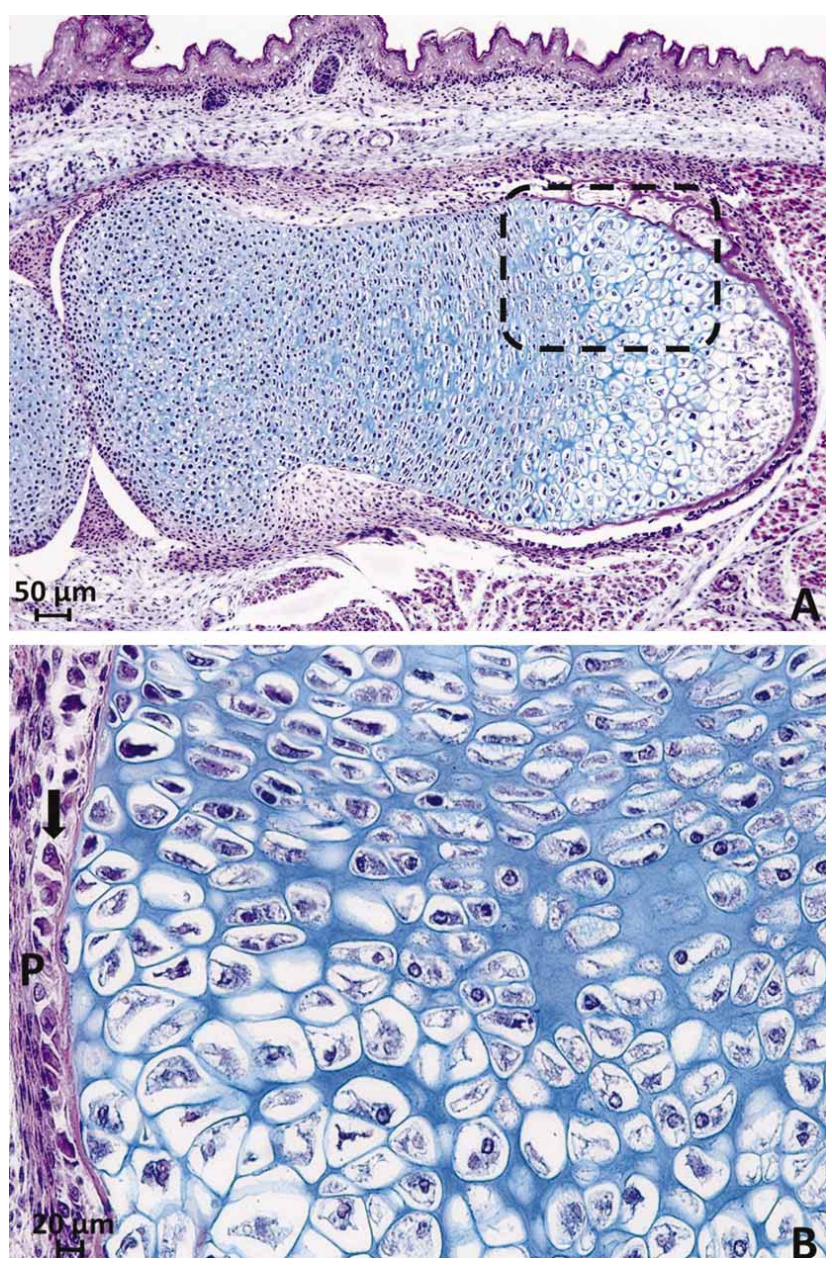

Fig. 1. A) osificación endocondral de fémur de ratón de 17 días (100X). B) aumento de la región seccionada de A, donde se observa la hiperplasia e hipertrofia de los condrocitos, además de un periostio (P) con osteoblastos en su capa interna (flecha) (400X). Técnica H-E con Azul de Alcián. 

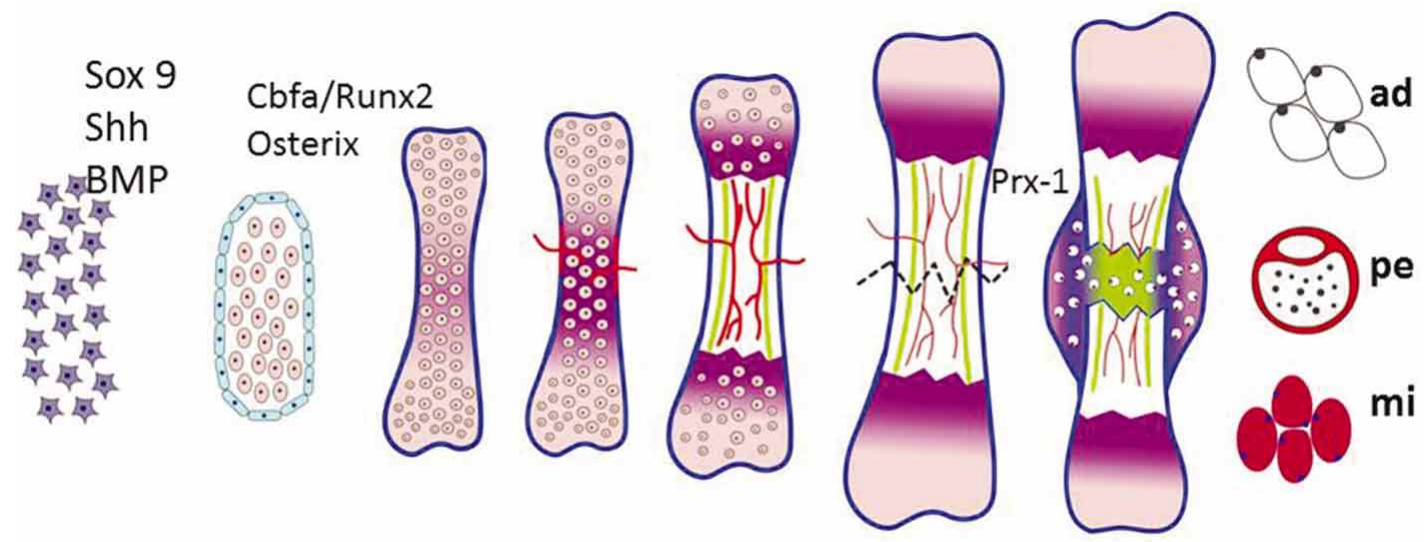

\section{A}

B

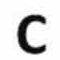

D

$\mathbf{E}$

G

Fig. 2. Esquema donde se muestra el aspecto básico molecular durante la embriogénesis y la regeneración ósea luego de una fractura. A) condensación de células mesenquimáticas. B) diferenciación de las células mesenquimáticas hacia la línea condrógena. C, D y E) Formación modelo cartilaginoso embrionario y posterior osificación endocondral. F) fractura a nivel de diáfisis de un hueso largo, activando al gen Prx-1 de las células multipotentes del periostio. G) formación del callo perióstico y diferenciación de sus células en adipocitos (ad), pericitos (pe) y miocitos (mi). Modificado de Colnot et al. (2012).
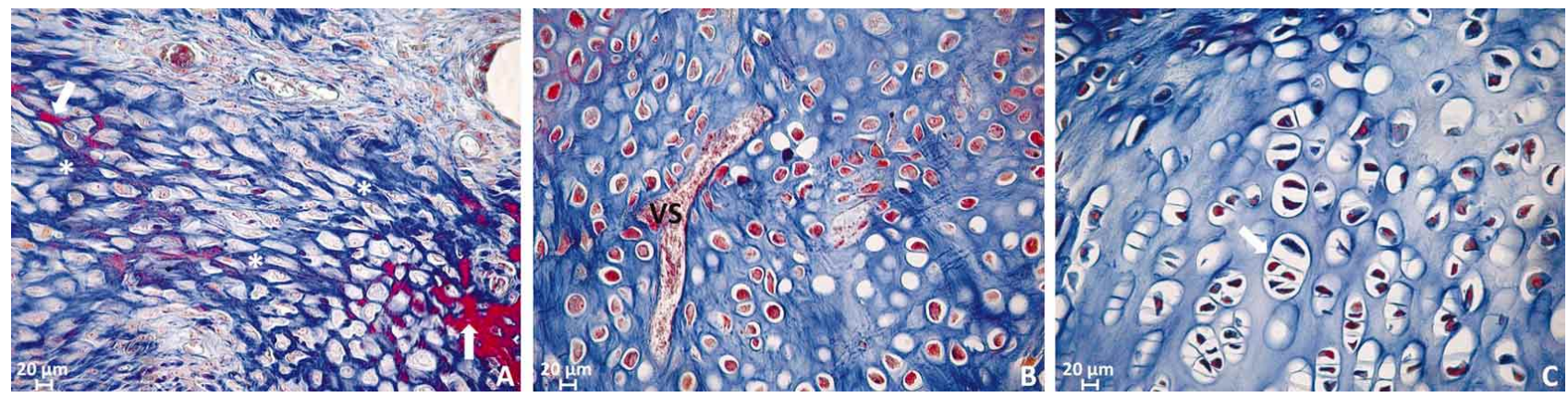

Fig. 3. Regeneración ósea en fractura de fémur de rata. A) Síntesis de MEC por parte de las células multipotentes provenientes del periostio (*) y calcificación de esta matriz (flechas). B) Formación de vasos sanguíneos (VS) dentro de la matriz cartilaginosa. C) Condrocitos en distintas fases del desarrollo. Se observa mitosis asimétrica de los condrocitos hipetrofiados (flecha). Técnica Tricrómico, 400X.

do la apoptosis de los condrocitos terminales, la digestión de la matriz extracelular, y la resorción de las espículas cartilaginosas calcificadas por parte de los osteoclastos mediante la producción de MMP9 (Krane \& Inada, 2008; Weatherholt et al., 2013; Maes, 2013; Smok et al., 2014; Tsang et al.). Autores como Fuchs \& Steller (2011); y Tsang et al., reconocen que la apoptosis es sólo una forma de la muerte celular programada, siendo el otro la autofagia. Además, no se descarta la posibilidad que los condrocitos hipertróficos sigan un camino de diferenciación hacia osteoblastos, proponiendo que los condrocitos hipertróficos experimentan una mitosis asimétrica (Fig. 3C), dando origen a una célula que entra en apoptosis y a otra que sobrevive diferenciándose a osteoblasto dependiendo del medio ambiente que lo rodea (Roach, 1997; Tsang et al.), siendo los condrocitos periféricos los que están expuestos a un microambiente que promueve la osteogénesis, mientras que en la porción central del cartílago los condrocitos mueren (Bianco et al., 1998; Tsang et al.). Esto es debido a que el FGF-18 producido por el pericondrio inhibe la maduración de los condrocitos alrededor de la periferia del cartílago, permitiendo que los condrocitos centrales sufran hipertrofia (Carlson).

Autores como Claes et al. (2012), creen que todos los osteoblastos involucrados en la osificación derivan de células precursoras periostales, al igual que Weatherholt et al., quienes afirman que no se observan células precursoras en el endostio, y Chang \& Knothe Tate (2012) y Colnot et al., al informar que toda la población de osteoblastos dentro del hueso derivan del pericondrio embrionario. Knight \& Hankenson (2013) y Smok et al. evidenciaron que estas células provienen tanto del periostio, como del endostio y de la médula ósea. 
Los osteoclastos observados que experimentan resorción y rodean las trabéculas neoformadas, producen las lagunas de resorción (lacuna erosionis) en el tejido donde ejercen su acción (Fig. 4A). Según Maes, VEGF induce la migración de los monocitos (vía VEGFR-1), mientras que Dai \& Rabie (2007), y Marini et al., establecen que además puede regular su diferenciación, sobrevivencia y función. Por otro lado, Taichman (2005) y Kierszenbaum \& Tres mencionan que la proliferación, maduración e inhibición de los osteoclastos son inducidas por los osteoblastos. Esto estaría dado por la liberación del factor estimulante de colonias de monocitos (M-CSF) por parte de los osteoblastos, el cual induce la migración y proliferación de los monocitos sanguíneos. La fusión de los monocitos genera osteoclastos inmaduros, los cuales maduran mediante la vía de transmisión de señales RANKL, liberado por los osteoblastos, los condrocitos hipertrofiados y algunas células estromales de la médula ósea (Takamoto et al., 2003; Masuyama et al., 2006). Esta activación es

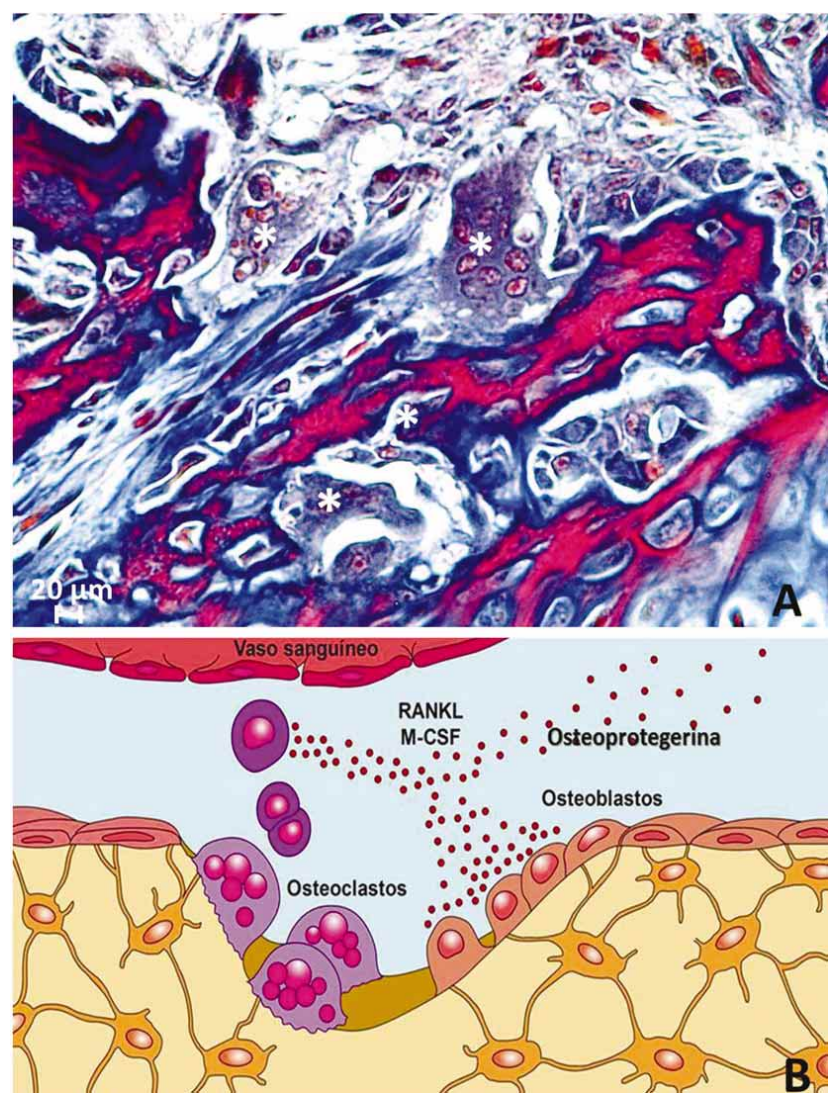

Fig. 4. Osteoclastos durante la remodelación ósea. A) Osteoclastos (*) rodeando las trabéculas óseas durante la remodelación ósea en fémur de rata.Técnica Tricómico, 400X. B) Esquema de la osteoclastogenia y los factores involucrados. Los osteoblastos inducen la activación y maduración de los osteoclastos mediante la liberación de RANKL y M-CSF, y además inhiben esta activación mediante la liberación de osteoprotegerina. Modificado Weatherholt et al. (2013). inhibida mediante la proteína osteoprotegerina, también elaborada por los osteoblastos. Una vez activados, los osteoclastos adquieren polaridad y forman una membrana rugosa sobre la superficie ósea, la cual representaría el transporte de las vesículas ácidas y su inserción a la membrana plasmática a través del uso de integrinas (Teitelbaum, 2000; Weatherlot et al.) (Fig. 4B).

El inicio de la reparación de una fractura se caracteriza por la infiltración de células inflamatorias, las que secretan citoquinas (entre las cuales se encuentran IL-1, IL2, RANKL y TNF (Shapiro), y factores de crecimiento importantes para la neovascularización (Street et al., 2002) y el reclutamieno celular (Gerstenfeld et al., 2003). Además se ha demostrado la presencia de macrofagocitos durante esta fase tanto en humanos (Andrew et al., 1994; Oni, 1997), como en animales (Hankemeier et al., 2001; Alexander et al., 2011; Raggatt et al.).
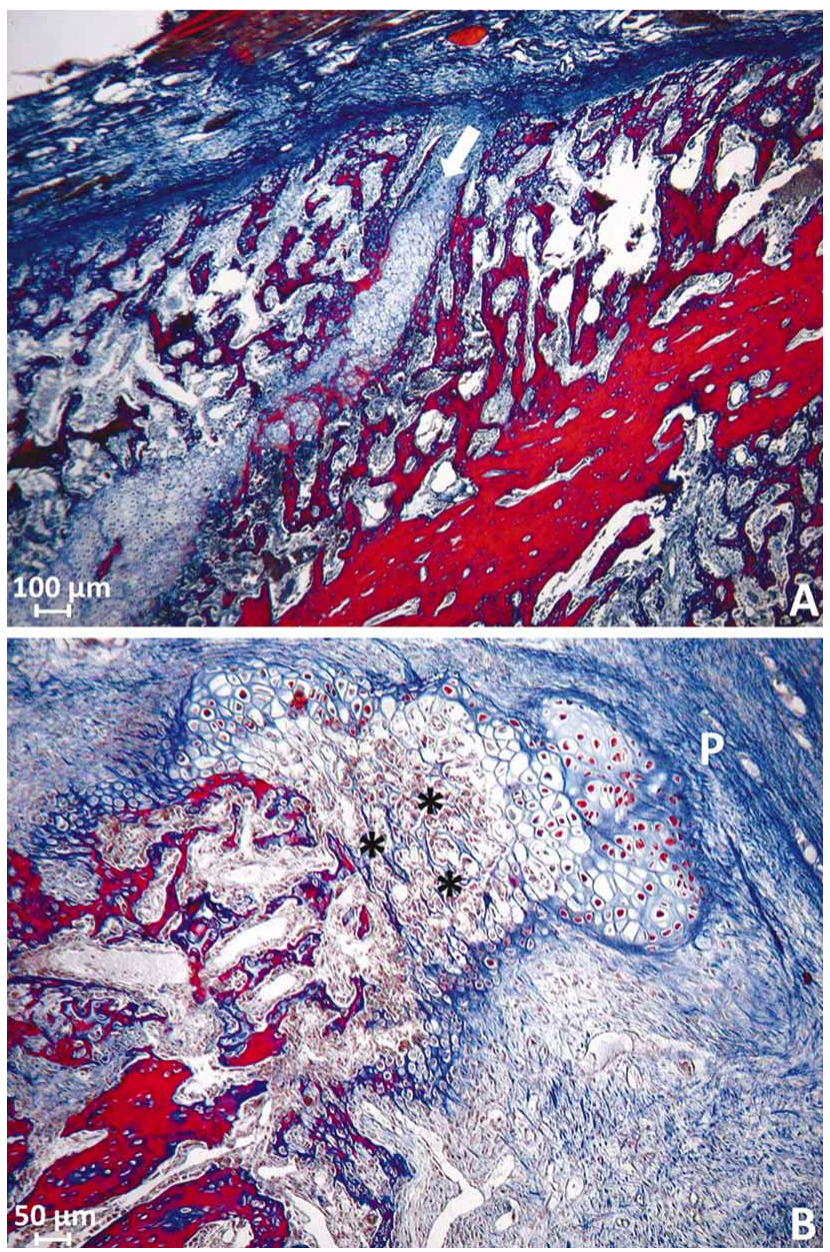

Fig. 5. Callo perióstico secundario de fractura de fémur de rata. A) Columna cartilaginosa (flecha) emergiendo desde el periostio (50X). B) Foco de cartílago rodeado de pericondrio (P), con formación de trabéculas óseas en su interior $(*)$ (100X). Técnica Tricrómico. 
Si la osteosíntesis no estabiliza, la fractura rígidamente, la reparación ocurre mediante la generación de un callo perióstico secundario, el cual se forma entre los 7 a 10 días luego de la fractura (Claes et al., 2006; Claes et al., 2012). El callo se encuentra constituido principalmente por tejido conectivo denso irregular, muy vascularizado y con gran cantidad de células de aspecto mesenquimal en el sitio de la fractura. Éste se puede formar directamente desde el periostio (Fig. 5A), o del hueso preformado del borde de la fractura. En un inicio se conforma como callo blando, con variables focos de tejido cartilaginoso, que se generan $\sin$ establecer un patrón espacial dentro del callo, para luego ser reemplazado por trabéculas óseas (Fig. 5B) (Smok et al.). Este callo involucra cantidades variables de osificación membranosa y principalmente endocondral (Schindeler $e t$ al., 2008), identificándose 3 fases que la constituyen: inflamación, reparación y remodelación, similar a lo descrito por Schindeler et al., Murao et al., Weatherholt et al. y Raggatt et al. Este tejido comienza a formarse en una región donde no está ni el periostio ni la vascularización interrumpida (Utvåg et al., 2003; Claes et al., 2012; Knight \& Hankenson), y avanza hacia los extremos de la fractura para conformar un puente entre éstos, logrando la unión de la fractura. Además de todos estos procesos, Mirhadi et al., mencionan que la formación del callo es guiada por los condrocitos, y Weatherholt et al., indican la aparición de una gran masa cartilaginosa formando un callo interno y otro externo, para culminar con la maduración del tejido a hueso laminillar y posterior reabsorción del callo.
Knight \& Hankenson, observaron que tanto el cartílago como el hueso eran originados a partir del periostio, similar a lo descrito por Smok et al. El periostio está conformado por una capa externa conectiva muy vascularizada (estrato fibroso), y una capa interna con osteoblastos que contribuyen a la formación y progresión del callo perióstico (estrato osteogénico) (Wang et al., 2011; Ito et al., 2014; Smok et al.).

Diversos autores coincidimos en que la regeneración del tejido óseo sigue el modelo de diferenciación embrionario (Ferguson et al.; Shapiro; Shintaku et al.; Soung do et al.; Smok et al.). Dado que el aspecto histológico de la reparación del hueso es semejante al desarrollo en las distintas fases del tejido cartilaginoso y de un hueso normal, formándose en primera instancia hueso no laminillar debido a la velocidad de regeneración, que impide la deposición ordenada de las fibras de colágeno propias del hueso laminillar (Currey, 2003; Weatherholt et al.). Además de la semejanza de formación, la participación molecular también lo es, probablemente igual (Einhorn; Barnes et al., 1999). Esta similitud ha sido descrita en varios reportes (Vortkamp et al., 1998; Ferguson et al.; Gerstenfeld et al.).

Con la presente revisión podemos concluir que ambos eventos están íntimamente relacionados durante la ontogenia del individuo, tanto morfológica como molecularmente, con la excepción del proceso inflamatorio y posterior callo perióstico secundario generado luego de una injuria.

SMOK, C. \& ROJAS, M. Similarities between ontogeny and post-fracture bone regeneration. Int. J. Morphol., 34(4):12931299, 2016.

SUMMARY: Bone ossification is a process that occurs during embryogenesis when fetal period begins. It is characterized by a condensation of mesenchymal cells with chondro and osteogenic bipotentiality, to form bone tissue by endochondral and membranous ossification respectively. Bone regeneration is the response generated in order to obtain the return of tissue after a trauma. This event is characterized by the formation of a secondary periosteal callus, which follows embryonic osteogenesis patterns introducing both types of ossification, besides their own molecular regulation during the fetal stage, concluding that both processes are closely related during ontogeny of the specimen, with the exception of the inflammatory process generated after an injury.

KEY WORDS: Ossification; Regeneration; Bone fractures.

\section{REFERENCIAS BIBLIOGRÁFICAS}

Alexander, K. A.; Chang, M. K.; Maylin, E. R.; Kohler, T.; Müller, R.; Wu, A. C.; Van Rooijen, N.; Sweet, M. J.; Hume, D. A.; Raggatt, L. J. \& Pettit, A. R. Osteal macrophages promote in vivo intramembranous bone healing in a mouse tibial injury model. J. Bone Miner. Res., 26(7):1517-32, 2011.

Andrew, J. G.; Andrew, S. M.; Freemont, A. J. \& Marsh, D. R. Inflammatory cells in normal human fracture healing. Acta Orthop. Scand.,65(4):462-6, 1994.
Arvidson, K.; Abdallah, B. M.; Applegate, L. A.; Baldini, N.; Cenni, E.; Gomez-Barrena, E.; Granchi, D.; Kassem, M.; Konttinen, Y. T.; Mustafa, K.; Pioletti, D. P.; Sillat, T. \& Finne-Wistrand, A. Bone regeneration and stem cells. J. Cell. Mol. Med., 15(4):718-46, 2011.

Athanasopoulos, A. N.; Schneider, D.; Keiper, T.; Alt, V.; Pendurthi, U. R.; Liegibel, U. M.; Sommer, U.; Nawroth, P. P.; Kasperk, C. \& Chavakis, T. Vascular endothelial growth factor (VEGF)- 
induced up-regulation of CCN1 in osteoblasts mediates proangiogenic activities in endothelial cells and promotes fracture healing. J. Biol. Chem., 282(37):26746-53, 2007.

Barnes, G. L.; Kostenuik, P. J.; Gerstenfeld, L. C. \& Einhorn, T. A. Growth factor regulation of fracture repair. J. Bone Miner. Res., 14(11):1805-15, 1999.

Bianco, P.; Cancedda, F. D.; Riminucci, M. \& Cancedda, R. Bone formation via cartilage models: the "borderline" chondrocyte. Matrix Biol., 17(3):185-92, 1998.

Carlson, B. Embriología Humana y Biología del Desarrollo. 5a ed., Barcelona, Elsevier, 2014.

Carmeliet, P. \& Jain, R. K. Molecular mechanisms and clinical applications of angiogenesis. Nature, 473(7347):298-307, 2011.

Chang, H. \& Knothe Tate, M. L. Concise review: the periosteum: tapping into a reservoir of clinically useful progenitor cells. Stem Cells Transl. Med., 1(6):480-91, 2012.

Claes, L.; Maurer-Klein, N.; Henke, T.; Gerngross, H.; Melnyk, M. \& Augat, P. Moderate soft tissue trauma delays new bone formation only in the early phase of fracture healing. J. Orthop. Res., 24(6):1178-85, 2006.

Claes, L.; Recknagel, S. \& Ignatius, A. Fracture healing under healthy and inflammatory conditions. Nat. Rev. Rheumatol., 8(3):13343, 2012.

Clarkin, C. E. \& Gerstenfeld, L. C. VEGF and bone cell signalling: an essential vessel for communication? Cell Biochem. Funct., 31(1):1-11, 2013.

Colnot, C.; Zhang, X. \& Knothe Tate, M. L. Current insights on the regenerative potential of the periosteum: molecular, cellular, and endogenous engineering approaches. J. Orthop. Res., 30(12):1869-78, 2012.

Córdova, L. A. Reparación Ósea Mandibular con Autoinjerto Ilíaco: Estudio Celular Inicial en el Modelo Animal Oryctolagus cuniculus. Tesis Magíster en Ciencias Biológicas, Mención Morfología. Santiago de Chile, Facultad de Medicina, Universidad de Chile, 2010.

Currey, J. D. The many adaptations of bone. J. Biomech., 36(10):1487-95, 2003.

Davies, J. E. \& Hosseini, M. M. Histodynamics of Endosseous Wound Healing. In: Davies, J. E. (Ed.). Bone Engineering. Toronto, EM Squared, 2000. pp.1-14.

Dai, J. \& Rabie, A. B. VEGF: an essential mediator of both angiogenesis and endochondral ossification. J. Dent. Res., 86(10):937-50, 2007.

Day. S. M.; Ostrum, R. F.; Chao, E. Y.; Rubin, C. T.; Aro, H. T. \& Einhorn, T. A. Bone Injury, Regeneration, and Repair. In: Buckwalter, J. A.; Einhorn, T. A. \& Simon, S. R. (Eds.).
Orthopaedic Basic Science. 2nd ed. Rosemont, American Academy of Orthopaedic Surgeons, 2000. pp.371-99.

Einhorn, T. A. The cell and molecular biology of fracture healing. Clin. Orthop. Relat. Res., (355 Suppl.):S7-21, 1998.

Ferguson, C.; Alpern, E.; Miclau, T. \& Helms, J. A. Does adult fracture repair recapitulate embryonic skeletal formation? Mech. Dev., 87(1-2):57-66, 1999.

Fernández-Tresguerres-Hernández-Gil, I.; Alobera-Gracia, M. A.; del-Canto-Pingarrón, M. \& Blanco-Jerez, L. Physiological bases of bone regeneration I. Histology and physiology of bone tissue. Med. Oral Patol. Oral Cir. Bucal, 11(1):E47-51, 2006.

Frost, H. M. The biology of fracture healing. An overview for clinicians. Part I. Clin. Orthop. Relat. Res., (248):283-93, 1989.

Fuchs, Y. \& Steller, H. Programmed cell death in animal development and disease. Cell, 147(4):742-58, 2011.

Gerstenfeld, L. C.; Cullinane, D. M.; Barnes, G. L.; Graves, D. T. \& Einhorn, T. A. Fracture healing as a post-natal developmental process: molecular, spatial, and temporal aspects of its regulation. J. Cell Biochem., 88(5):873-84, 2003.

Glynn, E. R.; Londono, A. S.; Zinn, S. A.; Hoagland, T. A. \& Govoni, K. E. Culture conditions for equine bone marrow mesenchymal stem cells and expression of key transcription factors during their differentiation into osteoblasts. J. Anim. Sci. Biotechnol., 4(1):40, 2013.

Grellier, M.; Ferreira-Tojais, N.; Bourget, C.; Bareille, R.; Guillemot, F. \& Amédée, J. Role of vascular endothelial growth factor in the communication between human osteoprogenitors and endothelial cells. J. Cell Biochem., 106(3):390-8, 2009.

Hankemeier, S.; Grässel, S.; Plenz, G.; Spiegel, H. U.; Bruckner, P. $\&$ Probst, A. Alteration of fracture stability influences chondrogenesis, osteogenesis and immigration of macrophages. J. Orthop. Res., 19(4):531-8, 2001.

Hsiong, S. X. \& Mooney, D. J. Regeneration of vascularized bone. Periodontol. 2000, 41:109-22, 2006.

Ito, R.; Matsumiya, T.; Kon, T.; Narita, N.; Kubota, K.; Sakaki, H.; Ozaki, T.; Imaizumi, T.; Kobayashi, W. \& Kimura, H. Periosteum-derived cells respond to mechanical stretch and activate Wnt and BMP signaling pathways. Biomed. Res., 35(1):69-79, 2014.

Kierszembaum, A. L. \& Tres, L. L. Histología y Biología Celular. Introducción a la Anatomía Patológica. 3a ed. Amsterdam, Elsevier Saunders, 2012.

Knight, M. \& Hankenson, K. Mesenchymal stem cells in bone regeneration. Adv. Wound Care (New Rochelle), 2(6):306-16, 2013.

Krane, S. M. \& Inada, M. Matrix metalloproteinases and bone. Bone, 43(1):7-18, 2008. 
Maes, C. Role and regulation of vascularization processes in endochondral bones. Calcif. Tissue Int., 92(4):307-23, 2013.

Marini, M.; Bertolai, R.; Ambrosini, S.; Sarchielli, E.; Vannelli, G. B. \& Sgambati, E. Differential expression of vascular endothelial growth factor in human fetal skeletal site-specific tissues: Mandible versus femur. Acta Histochem., 117(3):228-34, 2015.

Martin, J. F. \& Olson, E. N. Identification of a prx1 limb enhancer. Genesis, 26(4):225-9, 2000.

Masuyama, R.; Stockmans, I.; Torrekens, S.; Van Looveren, R.; Maes, C.; Carmeliet, P.; Bouillon, R. \& Carmeliet, G. Vitamin D receptor in chondrocytes promotes osteoclastogenesis and regulates FGF23 production in osteoblasts. J. Clin. Invest., 116(12):3150-9, 2006.

Mirhadi, S.; Ashwood, S. \& Karagkevrekis, B. Factors influencing fracture healing. Trauma, 15(2):140-55, 2013.

Murao, H.; Yamamoto, K.; Matsuda, S. \& Akiyama, H. Periosteal cells are a major source of soft callus in bone fracture. J. Bone Miner. Metab., 31(4):390-8, 2013.

Oni, O. O. The early stages of the repair of adult human diaphyseal fractures. Injury, 28(8):521-5, 1997.

Raggatt, L. J.; Wullschleger, M. E.; Alexander, K. A.; Wu, A. C.; Millard, S. M.; Kaur, S.; Maugham, M. L.; Gregory, L. S.; Steck, R. \& Pettit, A. R. Fracture healing via periosteal callus formation requires macrophages for both initiation and progression of early endochondral ossification. Am. J. Pathol., 184(12):3192-204, 2014.

Roach, H. I. New aspects of endochondral ossification in the chick: chondrocyte apoptosis, bone formation by former chondrocytes, and acid phosphatase activity in the endochondral bone matrix. J. Bone Miner. Res., 12(5):795-805, 1997.

Schindeler, A.; McDonald, M. M.; Bokko, P. \& Little, D. G. Bone remodeling during fracture repair: The cellular picture. Semin. Cell Dev. Biol., 19(5):459-66, 2008.

Shapiro, F. Bone development and its relation to fracture repair. The role of mesenchymal osteoblasts and surface osteoblasts. Eur. Cell Mater., 15:53-76, 2008.

Shintaku, Y.; Murakami, T.; Yanagita, T.; Kawanabe, N.; Fukunaga, T.; Matsuzaki, K.; Uematsu, S.; Yoshida, Y.; Kamioka, H.; Takano-Yamamoto, T.; Takada, K. \& Yamashiro, T. Sox9 expression during fracture repair. Cells Tissues Organs, 194(1):38-48, 2011.

Smok, C.; Meruane, M. \& Rojas, M. Implantation of autologous stem cells derived from adipose tissue in rat bone fractures. Int. J. Med. Surg. Sci., 1(2):105-15, 2014.

Soung do, Y.; Talebian, L.; Matheny, C. J.; Guzzo, R.; Speck, M. E.; Lieberman, J. R.; Speck, N. A. \& Drissi, H. Runx1 dosedependently regulates endochondral ossification during skeletal development and fracture healing. J. Bone Miner. Res., 27(7):1585-97, 2012.

Street, J.; Bao, M.; deGuzman, L.; Bunting, S.; Peale, F. V. Jr.; Ferrara, N.; Steinmetz, H.; Hoeffel, J.; Cleland, J. L.; Daugherty, A.; van Bruggen, N.; Redmond, H. P.; Carano, R. A. \& Filvaroff, E. $\mathrm{H}$. Vascular endothelial growth factor stimulates bone repair by promoting angiogenesis and bone turnover. Proc. Natl. Acad. Sci. U. S. A., 99(15):9656-61, 2002.

Taichman, R. S. Blood and bone: two tissues whose fates are intertwined to create the hematopoietic stem-cell niche. Blood, 105(7):2631-9, 2005.

Takamoto, M.; Tsuji, K.; Yamashita, T.; Sasaki, H.; Yano, T.; Taketani, Y.; Komori, T.; Nifuji, A. \& Noda, M. Hedgehog signaling enhances core-binding factor a1 and receptor activator of nuclear factor-kappaB ligand (RANKL) gene expression in chondrocytes. J. Endocrinol., 177(3):413-21, 2003.

Teitelbaum, S. Bone resorption by osteoclasts. Science, 289(5484):1504-8, 2000.

Tsang, K. Y.; Chan, D. \& Cheah, K. S. Fate of growth plate hypertrophic chondrocytes: Death or lineage extension? Dev. Growth Differ., 57(2):179-92, 2015.

Utvåg, S. E.; Grundnes, O.; Rindal, D. B. \& Reikerås, O. Influence of extensive muscle injury on fracture healing in rat tibia. $J$. Orthop. Trauma, 17(6):430-5, 2003.

Vortkamp, A.; Pathi, S.; Peretti, G. M.; Caruso, E. M.; Zaleske, D. J. \& Tabin, C. J. Recapitulation of signals regulating embryonic bone formation during postnatal growth and in fracture repair. Mech. Dev., 71(1-2):65-76, 1998.

Wang, Y.; Wan, C.; Gilbert, S. R, \& Clemens, T. L. Oxygen sensing and osteogenesis. Ann. N. Y. Acad. Sci., 1117:1-11, 2007.

Wang, Q.; Huang, C.: Xue, M. \& Zhang, X. Expression of endogenous BMP-2 in periosteal progenitor cells is essential for bone healing. Bone, 48(3):524-32, 2011.

Weatherholt, A.; Fuchs, R. K. \& Warden, S. J. Cortical and trabecular bone adaptation to incremental load magnitudes using the mouse tibial axial compression loading model. Bone, 52(1):372-9, 2013.

Dirección para correspondencia:

Dra. Mariana Rojas R.

Laboratorio de Embriología Comparada

Programa de Anatomía y Biología del Desarrollo

Facultad de Medicina, ICBM

Universidad de Chile

CHILE

E-mail: dramrojas@hotmail.com

Recibido : 06-07-2016

Aceptado: 17-09-2016 